\title{
Laser-inscribed Contact Lens Sensors for the Detection of Analytes in the Tear Fluid
}

\author{
Rosalia Moreddu ${ }^{1,2,}{ }^{*}$, James S. Wolffsohn ${ }^{3}$, Daniele Vigolo ${ }^{2}$, Ali K. Yetisen ${ }^{1}$ \\ ${ }^{1}$ Department of Chemical Engineering, Imperial College London, London, SW7 2AZ, UK \\ ${ }^{2}$ School of Chemical Engineering, University of Birmingham, Birmingham, B15 2TT, UK \\ ${ }^{3}$ School of Life and Health Sciences, Aston University, Birmingham, B4 7ET, UK
}

Keywords: Contact Lenses, biomarkers, tear fluid, biosensors, point-of-care diagnostics. 


\begin{abstract}
Tears exhibit compositional variations as a response to ocular and systemic metabolic conditions, and they can therefore be used for the assessment of physiological health. Here, microfluidic contact lenses were developed as wearable platforms for in situ tear $\mathrm{pH}$, glucose, protein, and nitrite ions sensing. The microfluidic system was inscribed in commercial contact lenses by $\mathrm{CO}_{2}$ laser ablation. The microchannel consisted on a central ring with four branches, and biosensors were embedded within microcavities located at the branches ends. The device was tested with artificial tears and colorimetric readouts were performed using a smartphoneMATLAB algorithm based on the nearest neighbor model. Sensors responded within a time range of 15 seconds, and yielded sensitivities of $12.23 \mathrm{~nm} / \mathrm{pH}$ unit, $1.4 \mathrm{~nm} / \mathrm{mmolL}^{-1}$ of glucose, 0.49 $\mathrm{nm} / \mathrm{gL}^{-1}$ of proteins, and $0.03 \mathrm{~nm} / \mu \mathrm{molL} \mathrm{L}^{-1}$ of nitrites. Contact lens sensing platforms may provide on-eye tears screening with applications in the monitoring of the ocular health both in clinics and at point-of-care settings.
\end{abstract}




\section{Introduction}

The tear fluid responds to ocular and systemic physiological conditions by exhibiting variations in the concentration of analytes. ${ }^{1-6}$ Tears nourish the proximal ocular tissues and expel the waste products of corneal metabolism. The tear fluid is composed of an outer lipid layer, secreted by the meibomian glands, a median aqueous layer, secreted by the lacrimal glands, and a mucin layer, produced by the conjunctival globet cells. ${ }^{7}$ The precorneal tear film is the portion of the fluid most relevant to corneal physiology and to drug penetration. ${ }^{8}$ Current tear examinations are external tests, conducted on pre-collected tear fluid samples. The gold standards for tear samples collection are the Shirmer's test ${ }^{9-10}$ and the capillary tube technique. ${ }^{11}$ The tear film has a thickness of $3 \mu \mathrm{m}$, a volume of $7 \mu \mathrm{L}$, a refractive index of 1.336 , and an osmolarity of $302 \pm 6.3 \mathrm{mOsm} / \mathrm{L} .{ }^{10}$ The tear fluid contains a mixture of different classes of non-polar and polar lipids, electrolytes, proteins, peptides, glucose, amino-acids, and O-linked carbohydrates with a protein core. ${ }^{1,3,9-10,12}$

The first human tear $\mathrm{pH}$ measurement was conducted in 1982 using a glass microelectrode and a reference electrode brought in contact with the anesthetized cornea. ${ }^{13}$ In 1990 , human precorneal tear film $\mathrm{pH}$ measurements were conducted using a fluorescent probe and determined noninvasively using pyranine, a $\mathrm{pH}$-sensitive fluorescent dye. ${ }^{8}$ Other techniques for $\mathrm{pH}$ measurement include micro-combinations glass probes inserted in the eye,${ }^{14}$ and microelectrodes. ${ }^{15}$ Healthy tear $\mathrm{pH}$ values range from 6.5 to $7.6 .{ }^{14}$ Tears are a buffer system that recovers its original $\mathrm{pH}$ in 7 minutes, in consistence with the wash out time of solutes in the conjunctival sac, in healthy 
conditions. ${ }^{8}$ Tear $\mathrm{pH}$ and buffering capacity were highlighted as parameters to estimate the ocular penetration of drugs. ${ }^{16}$ Contact lenses have been found not to alter tear buffering capacity. ${ }^{15} \mathrm{An}$ alkaline tear $\mathrm{pH}$ was suggested as a potential discriminant for the early diagnosis of rosacea, a common yet frequently undiagnosed condition of unknown aetiology, which induces corneal melting and stromal scarring., ${ }^{47}$ Rosacea is a chronic dermatosis which shows itself primarily in the skin, further invading eyelids and conjunctiva. However, early signs can be detected in the ocular environment (alkaline $\mathrm{pH} \approx 8$ ) before manifestations in the skin. ${ }^{17}$ The tear $\mathrm{pH}$ of nontreated ocular rosacea patients was found to be $8.0 \pm 0.32$, compared to $7.0 \pm 0.18$ in healthy controls. ${ }^{17}$ An altered tear buffering capacity was found in keratoconjunctivitis sicca patients. ${ }^{18}$ Tear $\mathrm{pH}$ was found to increase in pre- and post- operation senile cataract patients, resulting in $\mathrm{pH}$ values ranging from $7.26 \pm 0.23$ on the day before operation to $7.50 \pm 0.23$ on the first post-operative day. ${ }^{19}$

The typical protein concentration in tears is $3-7 \mu \mathrm{g} \mu \mathrm{L}^{-1}$, given by over 1500 different proteins, the 90\% of which include lysozyme, lipocalin, immunoglobulins, lactoferrin, sIgA, and proline richproteins. ${ }^{12,}{ }^{20-21}$ Tear lipocalin is the predominant phosphoprotein in human tear fluid. ${ }^{22}$ Tear proteomics has been extensively reported as a novel approach for the early diagnosis of a variety of disorders, including diabetic retinopathy, ${ }^{23-25}$ aniridia, ${ }^{26}$ and different dry eye aetiologies. ${ }^{27}$ Dry eye disease and microbial infections of the ocular surface have also been linked to ocular mucins levels. ${ }^{28}$ Tear proteomics has also been a topic of substantial speculation with regards to keratoconus. A two-fold decrease in total protein levels was observed in keratoconic tears (3.86 $\left.\mathrm{mg} \mathrm{mL} \mathrm{m}^{-1}\right)$ when compared to healthy controls $\left(7.00 \mathrm{mg} \mathrm{mL}^{-1}\right)$. Individual amounts of lactoferrin (0.67-0.28 vs. $\left.1.13-0.29 \mathrm{mg} \mathrm{mL}^{-1}\right)$ and secretory $\operatorname{IgA}\left(0.78-0.36\right.$ vs. $\left.1.70-0.66 \mathrm{mg} \mathrm{mL}^{-1}\right)$ were significantly reduced in tears of keratoconus patients. Monitoring the tear protein level is crucial 
for the early diagnosis and progression of keratoconus. ${ }^{29}$ The inhibition of proteolytic activity has been found to assist epithelial healing in patients with treatment-resistant corneal lesions. ${ }^{30}$

Healthy tears were reported to have nitrite levels of $120 \mu \mathrm{mol} \mathrm{L}{ }^{-1} \cdot{ }^{31}$ Nitric oxide is an important mediator of homeostatic processes in the eye, such as regulation of aqueous humor dynamics, retinal neurotransmission, and phototransduction. ${ }^{31}$ Changes in its generation or action may be associated to diverse inflammatory states, among which uveitis, retinitis, Behçet's syndrome, and degenerative diseases such as glaucoma. These changes can be monitored by measuring tear nitrites as nitric oxide byproducts. This resulted in a significant down-regulation of nitrites and nitrates, which concentrations were found reduced to a mean value of $80 \mu \mathrm{mol} \mathrm{L}{ }^{-1} \cdot{ }^{31}$ Behçet's syndrome is a multisystemic vasculitis which primary symptoms are oral and genital ulcers, skin lesions, and uveitis. In Behçet's patients both with and without ocular complications, tear nitric oxide was found to quickly oxidize in peroxynitrite, highly oxidizing cytotoxic substances. ${ }^{31}$ Nitrites and nitrates levels as nitric oxide cytotoxic end products were found to be significantly decreased in Behçet's patients, with average concentrations of $82.29 \mu \mathrm{mol} \mathrm{L}^{-1}$ in active Behçet's patients, compared to $109.17 \mu \mathrm{mol} \mathrm{L} \mathrm{L}^{-1}$ in healthy controls. ${ }^{31}$

Tears were extensively investigated as an alternative body fluid for the monitoring of body sugar levels in diabetic patients. ${ }^{32-33}$ The correlation between tear glucose and capillary blood glucose allows to determine the diabetic status of a subject exclusively using tear glucose values. ${ }^{32,34-35}$ Many efforts have been dedicated to the development of methods for tear glucose detection and monitoring, including glucose-sensitive photonic crystals, ${ }^{36}$ holographic sensors, ${ }^{37}$ and molecularly-imprinted fluorescent sensors. ${ }^{38}$ Glucose sensitive-contact lenses were also proposed. ${ }^{39-40}$ However, many of these methods are based on electrical readouts. ${ }^{41-43}$ Devices to detect tear analytes were also developed to be coupled to current tear collection methods. ${ }^{44-45}$ 
However, in all these cases tear samples are collected from the ocular surface and further injected and processed in such miniaturized devices, and tear collection methods have been found to alter the concentration of analytes. ${ }^{46-47}$

Establishing reliable methods for tear collection and processing is still an open challenge, due to the small volumes of unstimulated tear samples, and to the altered composition of stimulated tear samples. ${ }^{48}$ Wearable sensors have attracted particular interest in the last decades. ${ }^{49-51}$ Contact lenses offer several advantages to be used as wearable platforms to monitor the ocular physiology. ${ }^{39,52-53}$ Integrating biosensing functions within contact lenses with optical readouts allows in situ direct collection and detection with a minimally-invasive method and substantially reduced contamination risks. Here, semi-quantitative microfluidic contact lens sensors were developed for the detection of $\mathrm{pH}$, glucose, protein and nitrite levels in tears. Microchannels were etched in commercial rigid gas permeable (RGP) contact lenses by laser ablation, and colorimetric biochemical sensors were deposited over four sensing areas within the microfluidic system (Figure 1a). Upon binding tear metabolites, biochemical sensors exhibited a reflection peak shift in the visible spectrum, resulting in a color change visible with the naked eye. To achieve precision readout, biosensors were imaged using a smartphone camera (Figure 1b), and further processed using a MATLAB algorithm based on the nearest neighbor method, which outputted the concentration of analytes corresponding to the detected color (Figure 1c).
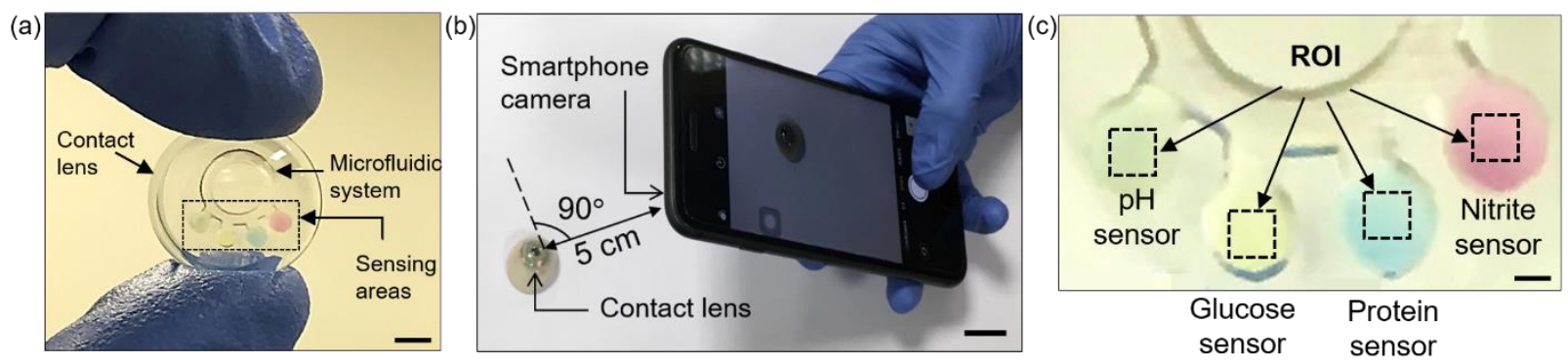
Figure 1. Microfluidic contact lenses for the colorimetric sensing of tear metabolites. (a) Photo of a contact lens sensing platform. Scale bar: $5.0 \mathrm{~mm}$. (b) The color change of the sensors is imaged using a smartphone camera. Scale bar: $1.0 \mathrm{~cm}$. (c) Photographs of the sensors serve as inputs to the customized MATLAB algorithm, where the region of interest (ROI) can be selected. Discrete concentration values are identified based on the comparison between the $(\mathrm{x}, \mathrm{y})$ coordinates defining the color in the CIE 1931 chromaticity space, and the position of the calibration points. Scale bar: $1.0 \mathrm{~mm}$.

\section{Results}

Tear fluid biosensors based on chromogenic compounds sensitive to $\mathrm{pH}$, glucose, proteins, and nitrites, were synthetized. The sensors exhibited a variation of the reflected light within the visible spectrum upon variations in the concentration of tear metabolites. The tear $\mathrm{pH}$ sensor was based on methyl red, bromothymol blue, and phenolphthalein (Figure 2a), and it reflected wavelengths in the green in neutral solution. Methyl red is an organic compound comprising a carboxylic acid group and an amine functional group, that confer it the ability to serve either as acid or base, and to detect $\mathrm{pH}$ variations from 4.3 to 6.2 . Bromothymol blue is a weak acid that forms triphenylmethane in alkaline media, reporting a shift in the reflected light from yellow to blue. Phenolphthalein switches from a colorless lactonic ring structure in acidic media to a quinoidcarboxylated structure in alkaline media. It exhibited a color shift from pink to fuchsia upon $\mathrm{pH}$ variations from 8.2 to 12.0 . The tear $\mathrm{pH}$ sensor was tested in aqueous solution in the physiological range of interest, at values of 6.0, 6.5, 7.0, 7.3, 7.6, 8.0. Figure $2 \mathbf{b}$ shows the absorbance spectra of tear $\mathrm{pH}$ sensors. The inset shows the calibration curve, from which a sensitivity of $12.23 \mathrm{~nm} / \mathrm{pH}$ 
and a LOD of $0.25 \mathrm{pH}$ units were calculated. The optical density (absorbance) trend at $610 \mathrm{~nm}$ (linear fitting, $\mathrm{R}^{2}=0.99$ ) is shown in Figure 2c. The inset figure shows the $\mathrm{pH}$-dependent color variation of the sensor, ranging from dark yellow at 6.0 to blue at 8.0 . These colors were used as calibration inputs to the MATLAB algorithm. The percentage of RGB colors over the $\mathrm{pH}$ value is shown in Figure 2d. The corresponding calibration points are plotted in the chromaticity diagram in Figure 2e. The algorithm processed the imaged biosensors embedded in contact lenses and calculated the related concentrations by locating the detected color in the chromaticity space, and comparing it to the position of the calibration points. The algorithm returned concentration values corresponding to the nearest calibration value in the diagram, compared to the color under examination. The nearest neighbor was calculated considering the point with the $(\mathrm{x}, \mathrm{y})$ shorter distance in the 2D CIE1931 chromaticity space. Figure $2 f$ presents the variation of (x, y) CIE 1931 coordinates over variations in $\mathrm{pH}$ values. The two coordinates are ideally expected to follow a reciprocal behavior. 
(a)

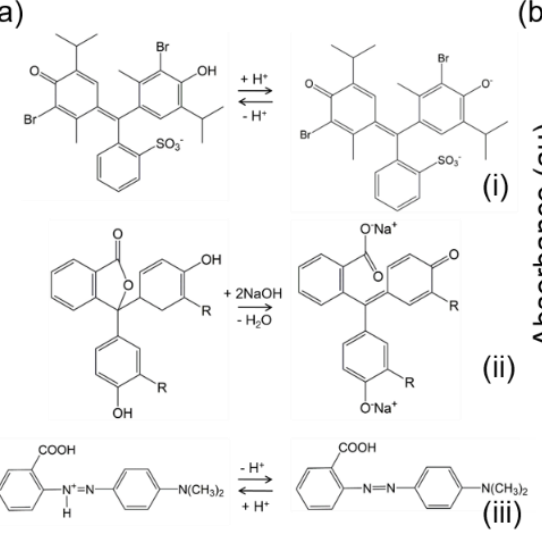

(d)

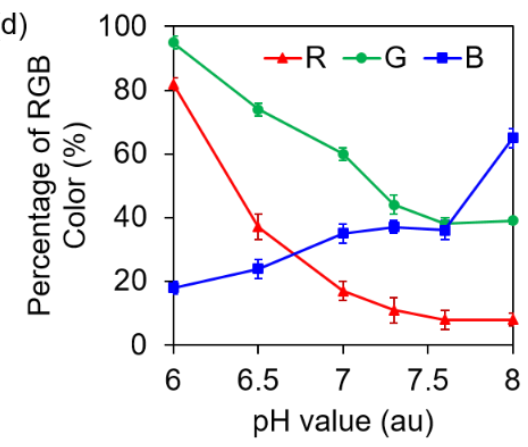

(b)

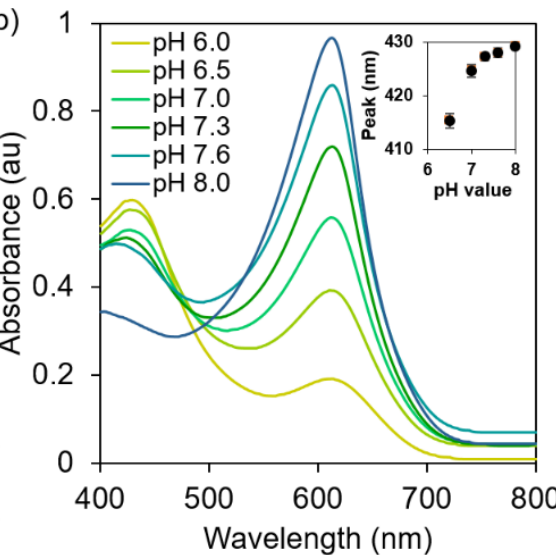

(e)

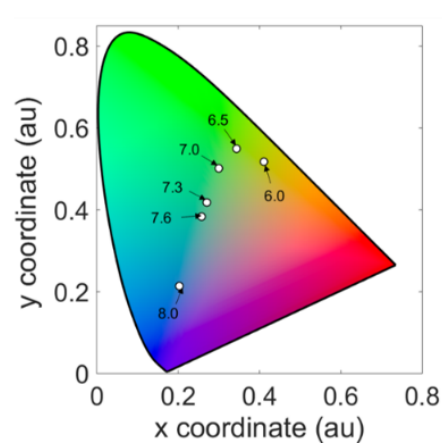

(c)
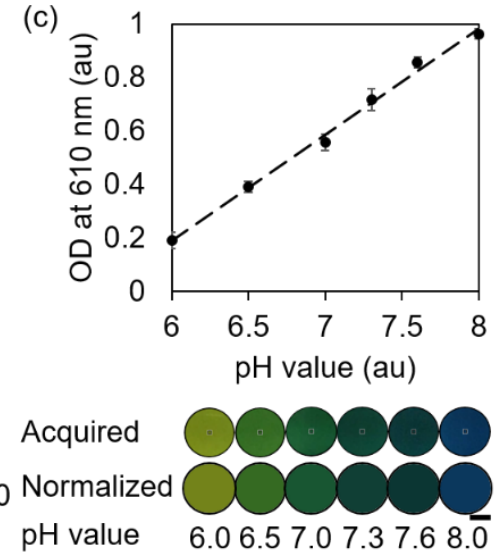

(f)

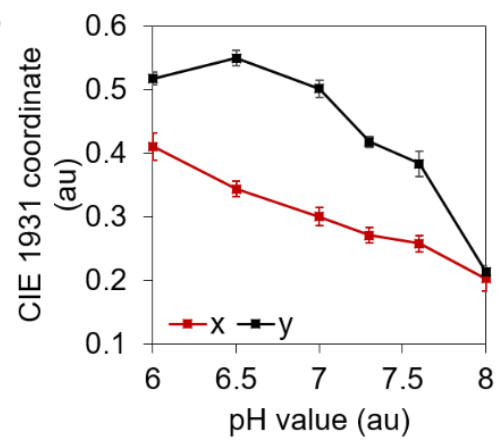

Figure 2. Characterization of the tear $\mathrm{pH}$ sensor. (a) Chemical structures of methyl red (i), bromothymol blue (ii), and phenolphthalein (iii). (b) Absorption spectra of 6.0, 6.5, 7.0, 7.3, 7.6, and $8.0 \mathrm{pH}$ buffers. The inset shows the calibration curve. (c) Optical density trend at $610 \mathrm{~nm}$. The inset figure shows the acquired (first row) and normalized (second row) colors imaged in solutions containing different concentrations of hydrogen ions. Scale bar: $500 \mu \mathrm{m}$. (d) Colorimetric characterization of $\mathrm{pH}$ sensors according to the RGB color model. (e) Chromaticity diagram displaying the calibration points. (f) Trend of the (x, y) coordinates at different $\mathrm{pH}$ levels, plotted in the CIE 1931 chromaticity space.

The tear glucose sensor was based on a two-step enzymatic method, using glucose oxidase/peroxidase (GOD/POD) (Figure 3a). The oxidation of D-glucose to D-gluconolactone in 
air forms hydrogen peroxide, which in turn oxidizes 3,3',5,5'-tetramethylbenzidin (TMB) under peroxidase catalysis. Tear glucose sensors yielded a color shift from yellow to different shades of green, upon varying glucose concentration from $0,2,5,10,15,20 \mathrm{mmol} \mathrm{L}^{-1}$. The absorbance spectra of the sensors tested in glucose PBS solutions at different concentrations are shown in Figure 3b. The calibration curve is shown in the inset, and yielded a sensitivity of $1.4 \mathrm{~nm} / \mathrm{mmolL}^{-}$ ${ }^{1}$ of glucose, and a LOD of $1.84 \mathrm{mmolL}^{-1}$. The optical density trend at $670 \mathrm{~nm}$ is shown in Figure 3c, with a second order polynomial fitting $\left(\mathrm{R}^{2}=0.99\right)$. The inset figure shows the colors of the different solutions as acquired with the smartphone applications, and the corresponding normalized pixels. These images were used as inputs to the MATLAB algorithm to identify the reference points. RGB triplets associated to each color are plotted in Figure 3d. The associated colors are plotted in the chromaticity diagram of Figure 3e. Figure $3 \mathbf{f}$ shows the behavior of the (x, y) CIE 1931 coordinates related to the calibration values. 
(a)

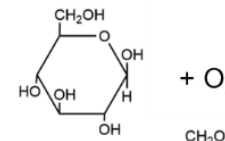
$\mathrm{H}_{2} \mathrm{O}_{2}+$
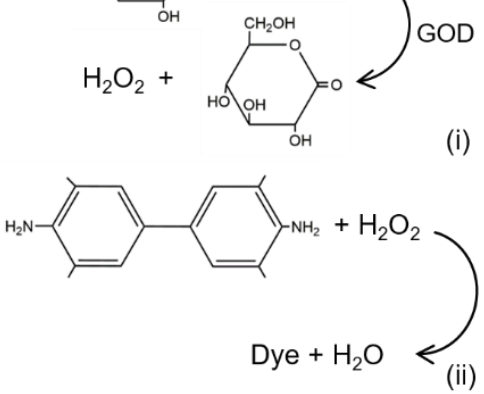

(ii)

(d)

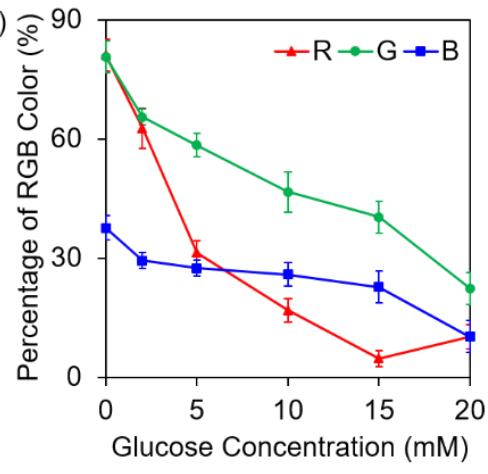

(b)

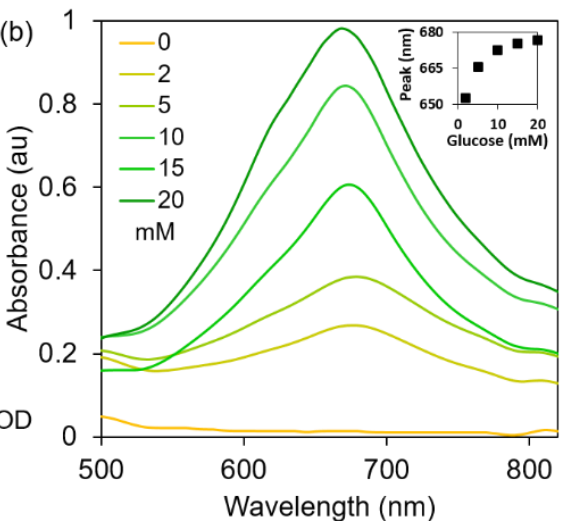

(e)

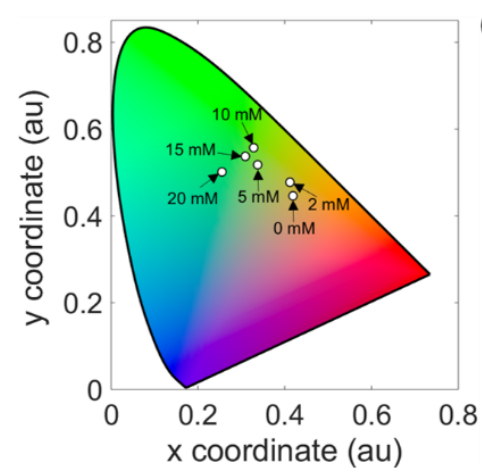

(f) (c)

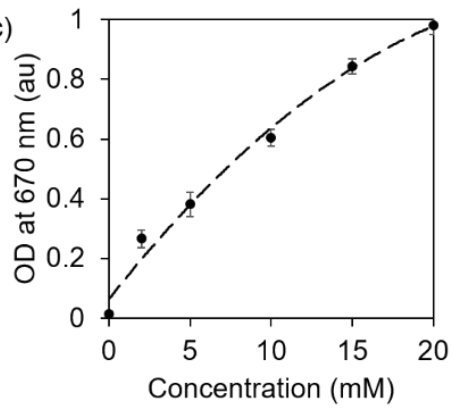

Acquired

Normalized

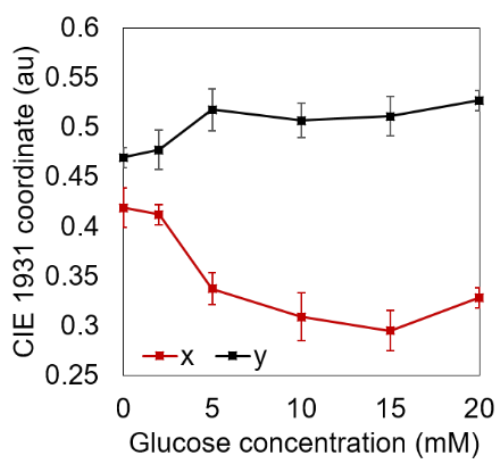

Figure 3. Characterization of the tear glucose sensor. (a) Working principle of the glucose biosensor. $\beta$-D glucose reacts with oxygen producing hydrogen peroxide (i), which oxidizes 3,3',5,5'-tetramethylbenzidin (ii). (b) Absorption spectra of solutions at glucose concentration of $0.0,2.0,5.0,10.0,15.0,20.0 \mathrm{mmol} \mathrm{L}^{-1}$. The inset shows the calibration curve. (c) Optical density trend of tear glucose sensors at $670 \mathrm{~nm}$. The inset figure shows the acquired (first row) and normalized (second row) colors imaged in solutions having different glucose concentration. Scale bar: $500 \mu \mathrm{m}$. (d) RGB characterization of glucose sensors. (e) Chromaticity diagram displaying the calibration points. (f) Trend of the (x,y) coordinates at different glucose levels, plotted in the CIE 1931 chromaticity space. 
Tear protein sensors were based on the reaction of $3^{\prime}, 3^{\prime \prime}, 5^{\prime}, 5^{\prime \prime}$-tetrachlorphenol-3,4,5,6tetrabromsulfophthalein with free amino groups (Figure 4a), that induced a color change from beige to light blue for protein concentration values of $0.5,1.0,2.0,3.0,4.0$ and $5.0 \mathrm{~g} \mathrm{~L}^{-1}$. Figure 4b shows the absorption spectra of tear protein sensors in PBS solutions at different concentration levels, and the corresponding calibration curve is plotted as an inset. The protein sensors yielded a sensitivity of $0.49 \mathrm{~nm} / \mathrm{gL}^{-1}$ of proteins, and a LOD of $0.63 \mathrm{gL}^{-1}$.

The optical density trend of the sensor with the second order polynomial fitting $\left(\mathrm{R}^{2}=0.97\right)$ is presented in Figure 4c. The inset figure shows the colors of the different solutions as acquired with the smartphone applications (first row), and the corresponding normalization (second row). These images were used as calibration colors for the MATLAB algorithm, from which concentrations in artificial tear fluid were estimated. RGB triplets associated to each color are plotted in Figure 4d. The associated colors are indicated in the chromaticity diagram of Figure 4e. Figure $4 \mathbf{f}$ shows the behavior of the (x, y) CIE 1931 coordinates. 
(a)
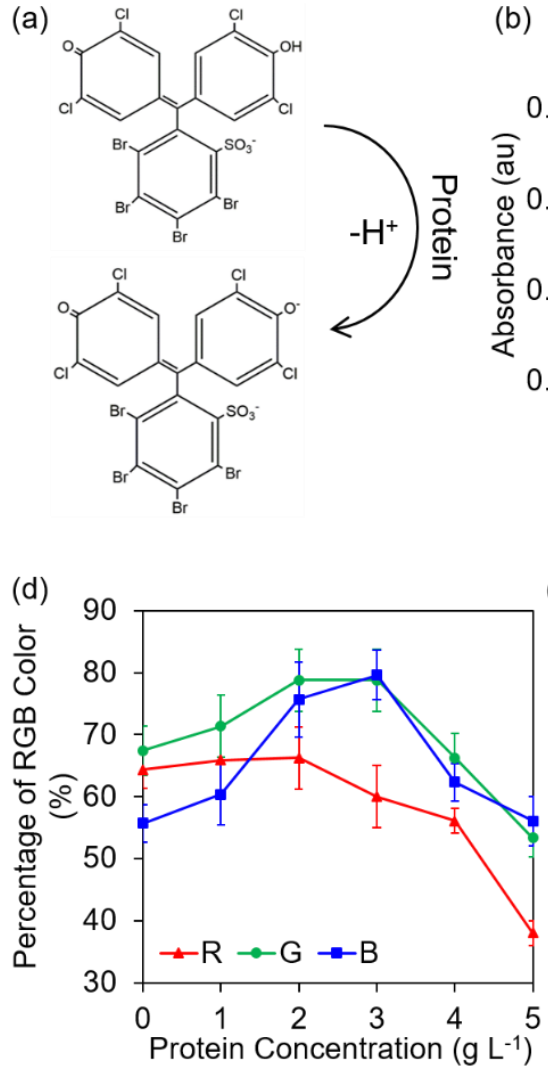

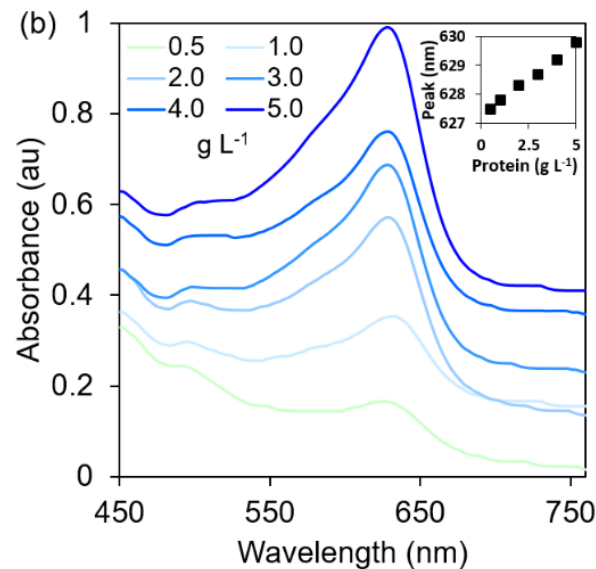

(e)

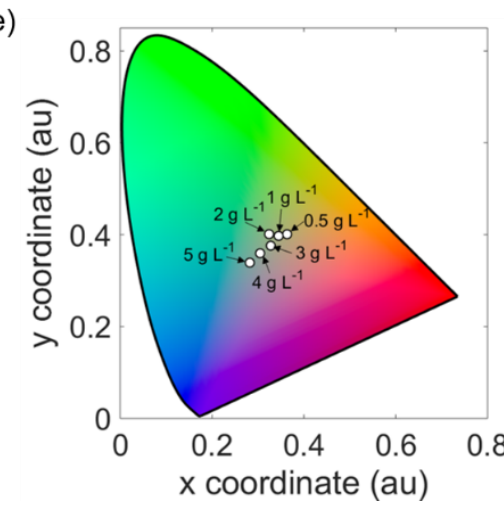

(c)

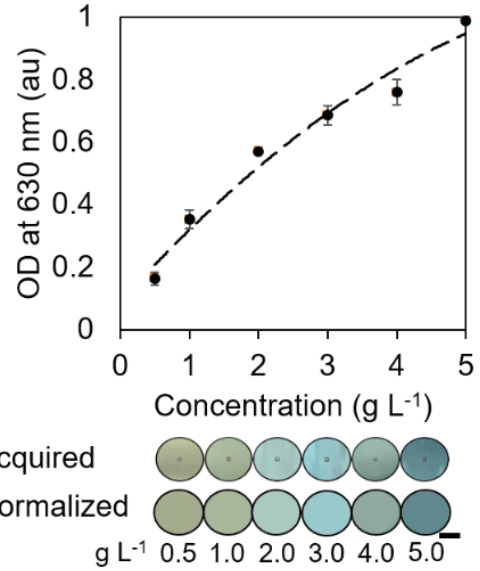

(f)

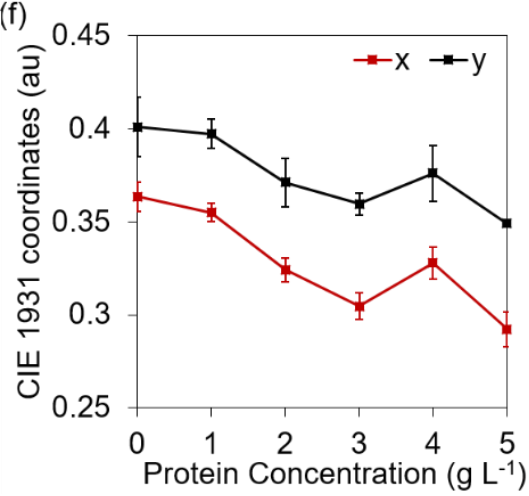

Figure 4. Characterization of the tear protein sensor. (a) Working principle of the protein biosensor. A 3',3",5',5"-tetrachlorphenol-3,4,5,6-tetrabromsulfophthalein molecule binds an amino-acidic hydrogen ion, yielding an anode of the same compound which reflects a different color. (b) Absorption spectra of solutions at protein concentrations of 0.5, 1.0, 2.0, 3.0, 4.0, and $5.0 \mathrm{~g} \mathrm{~L}^{-1}$. The inset shows the calibration curve. (c) Optical density trend of tear protein sensors at $630 \mathrm{~nm}$. The inset figure shows the acquired and normalized colors imaged in solutions having different protein concentration. Scale bar: $500 \mu \mathrm{m}$. (d) RGB characterization of protein sensors. (e) Chromaticity diagram displaying the calibration points. (f) Trend of the (x, y) coordinates at different protein levels, plotted in CIE 1931 chromaticity space. 
Tear nitrite sensors were based on the reaction of nitrite ions with sulfanilamide to form a diazonium salt, which further binds N-(1-naphthyl)- ethylenediamine dihydochloride (Figure 5a), to produce a pink azo dye yielding increasing intensities at higher concentrations of nitrite ions. The absorbance peak of the dye is measured at $528 \mathrm{~nm}$. The tear nitrite sensors were tested in aqueous solutions at nitrite concentrations of $0,10,20,80,120,150,180$, and $200 \mu \mathrm{mol} \mathrm{L}^{-1}$. Figure 5b shows the absorption spectra of tear nitrite sensors, and the calibration curve as an inset. The nitrite sensor yielded a sensitivity of $0.03 \mathrm{~nm} / \mu \mathrm{molL}^{-1}$ of nitrites, and a LOD of $24.4 \mu \mathrm{molL}^{-1}$. Figure 5c depicts the corresponding optical density trend at $510 \mathrm{~nm}$, with the second order polynomial fitting $\left(\mathrm{R}^{2}=0.99\right)$. The inset figure shows the acquired (first row) and normalized (second row) colors of the different solutions, which were given as inputs to the MATLAB algorithm to calibrate the outputs. The corresponding RGB triplets are plotted in Figure 5d. Chromogenic changes of the calibration points are indicated in the chromaticity diagram of Figure 5e. Figure 5f shows the behavior of the (x, y) CIE 1931 coordinates. At a concentration of 200 $\mu \mathrm{mol} \mathrm{L} \mathrm{L}^{-1}$, the coordinates stop following a reciprocal trend, indicating that the color change saturates and the variation is appreciated due to a color intensification only (as visible in the RGB characterization, with a substantial increase in the blue percentage at $200 \mu \mathrm{mol} \mathrm{L}-1)$. 
(a)
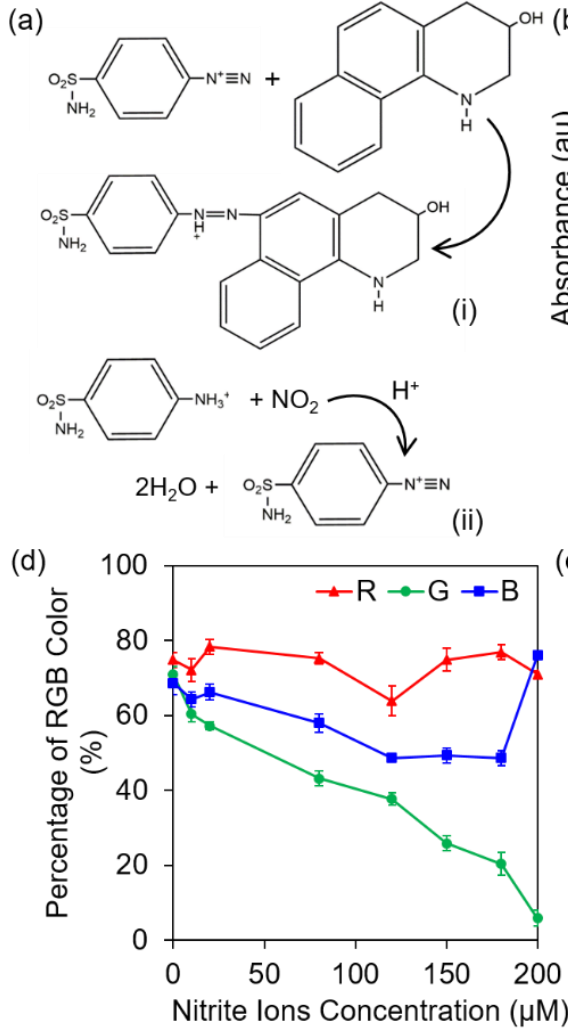

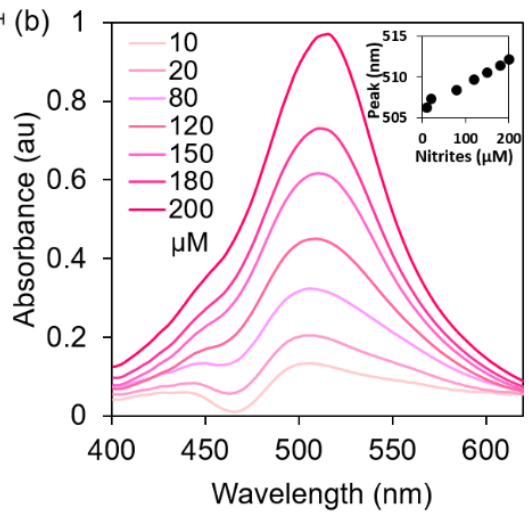

(e)

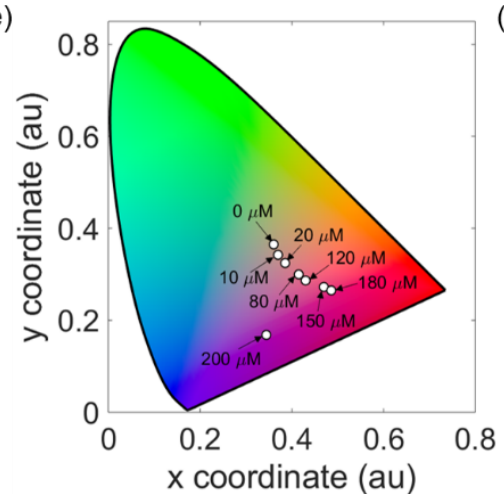

(c)
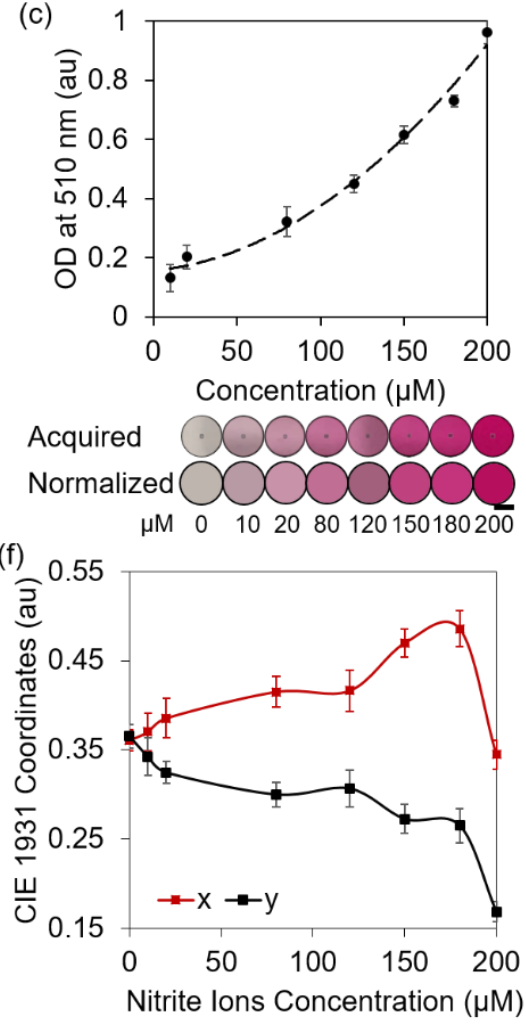

Figure 5. Characterization of the tear nitrite sensor. (a) Working principle of the nitrite biosensor. Nitrite ions react with sulfanilamide to form a diazonium salt (i), which in turn binds $\mathrm{N}-(1$ naphthyl)-ethylenediamine dihydochloride, producing a pink azo dye (ii). (b) Absorption spectra of solutions at nitrite concentration of 10.0, 20.0, 80.0, 120.0, 150.0, 180.0, and $200.0 \mu \mathrm{mol} \mathrm{L}^{-1}$. The inset shows the calibration curve. (c) Optical density trend of tear nitrite sensors at $510 \mathrm{~nm}$. The inset figure shows the acquired and normalized colors imaged in solutions having different nitrite concentration. Scale bar: $500 \mu \mathrm{m}$. (d) RGB characterization of nitrite sensors. (e) Chromaticity diagram displaying the calibration points. (f) Trend of the (x,y) coordinates at different nitrite levels, plotted in CIE 1931 chromaticity space. 
The tear metabolites sensors were embedded within laser-patterned microfluidic RGP commercial contact lenses, and characterized with artificial tear fluid. The microfluidic system was tested by injecting fluorescein aqueous solution (Figure 6a). Microchannels were filled with five continuous injections of $1.0 \mu \mathrm{L}$ each, resulting in the channel being fully filled in $560 \mathrm{~ms}$. Neutral tear biosensors were further embedded within microchannel cavities, and artificial tear fluid containing $5.0 \mathrm{~g} \mathrm{~L}^{-1}$ of protein standard, $5.0 \mathrm{mmol} \mathrm{L}^{-1}$ of glucose, $120 \mu \mathrm{mol} \mathrm{L}^{-1}$ of nitrite ions dissolved in a $\mathrm{pH} 8.0$ buffer solution and in artificial eye drops, was injected with five continuous injections of $1 \mu \mathrm{L}$ each. Figure $6 \mathbf{b}$ shows photographs of the contact lens platform before and 15 seconds after artificial tear fluid injection, where color changes are visible. Insets show optical micrographs of a cavity and a section of the microchannel, under $5 x$ magnification. The sensors were imaged with a smartphone camera kept normal to the contact lens sensing area, at a distance of $5.0 \mathrm{~cm}$ and ambient light conditions of 200 lux, to emulate what would happen in a real case scenario, where microfluidic channels would be created by bonding a second contact lens on top, and etching an inlet on the concave side of the contact lens sensor to directly access tear fluid from the patient's eye. Figure 6c shows photographs of the imaged sensors before and after artificial tear fluid injection, that were processed with the MATLAB algorithm. To evaluate the time response of each sensor, RGB color shift were examined over time (Figure 6d), resulting in a color saturation of the $\mathrm{pH}$ sensor after $5 \mathrm{~s}$, and time responses of $15 \mathrm{~s}, 10 \mathrm{~s}$, and $15 \mathrm{~s}$, for glucose, protein, and nitrite sensors, respectively. Insets in figures show the color change at the considered discrete time intervals. Figure 6e displays the CIE 1931 chromaticity diagrams observable while operating the algorithm during image processing. The region of interest is selected within the imaged sensing area. The corresponding normalized color is plotted in the chromaticity space, where it is compared to the position of the calibration points. The value of the unknown concentration is given by 
considering the calibration point with the shortest distance from the point under analysis. This method guarantees a correct output for discrete concentration values, defined during the calibration step, when performing the measurement in the same light conditions. This would be a realistic scenario when operating the device inside a medical clinic room. However, this algorithm may be improved to estimate intermediate concentration values. The box plots in Figure $\mathbf{6} \mathbf{f}$ display the expected concentration values versus the concentrations detected with smartphone-MATLAB readouts, before and after artificial tear fluid injection. Standard errors were calculated by measuring the $(\mathrm{x}, \mathrm{y})$ distance between the color under measurement and its nearest calibration point in the chromaticity diagram, and they were plotted in the y secondary axis. $\mathrm{pH}$ sensing in artificial tear fluid yielded mean standard errors of $2.0 * 10^{-2}$ and $2.3 * 10^{-2}$ before and after injection, respectively. Glucose, protein and nitrites had null concentrations before injection. After injection, they yielded mean standard errors of $1.2 * 10^{-2}, 2.0 * 10^{-3}$, and $1.3 * 10^{-2}$. 

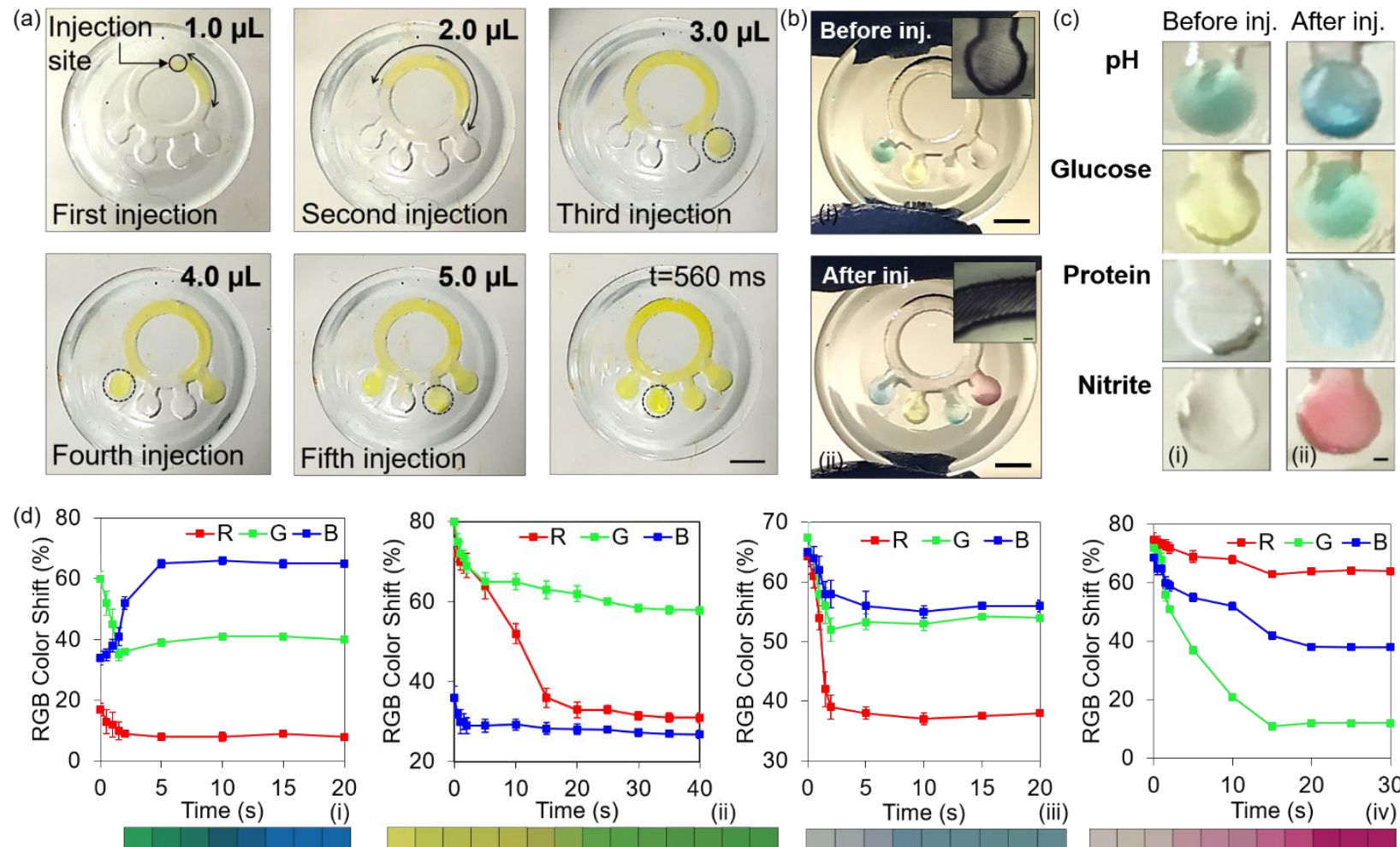

(e)
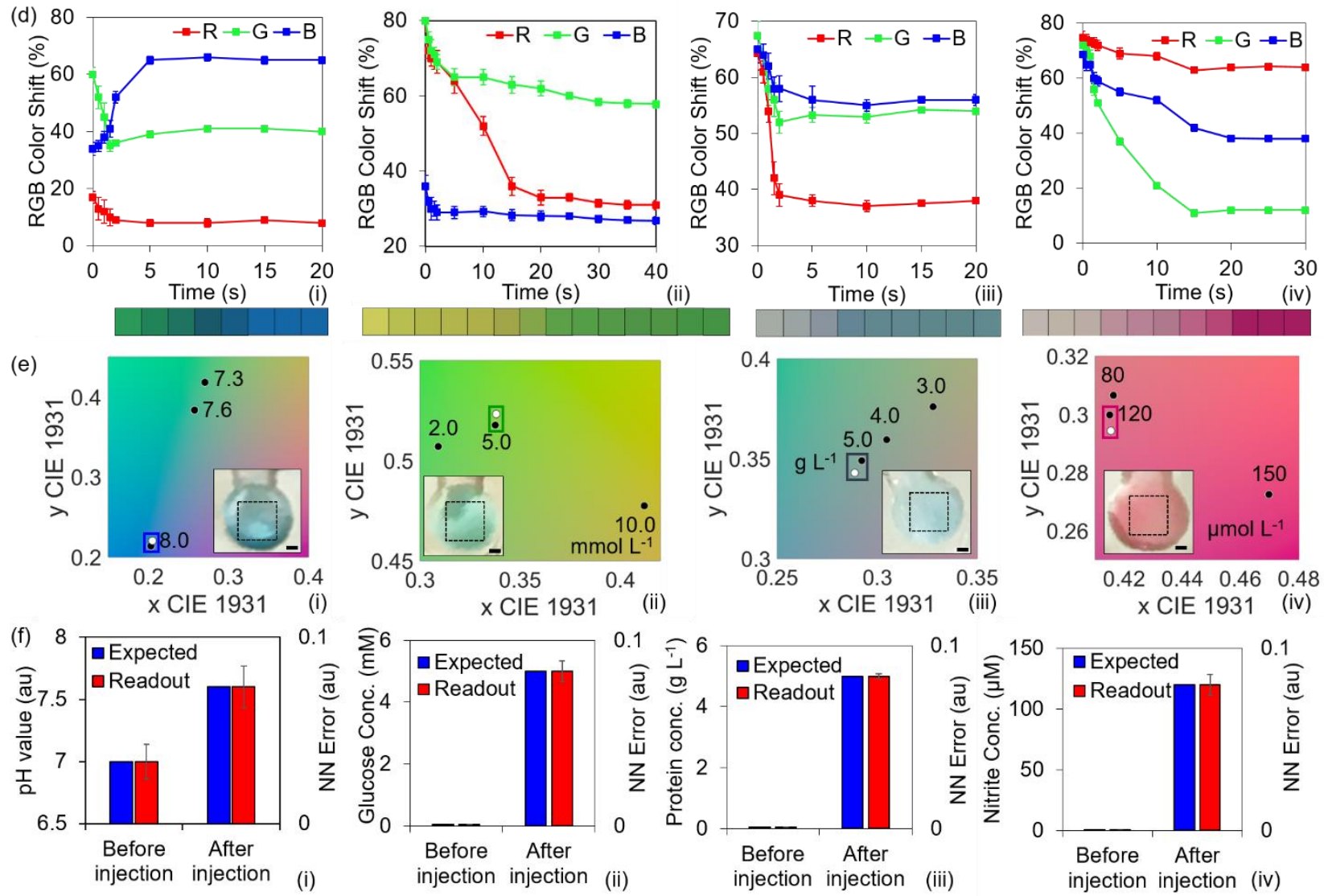

Figure 6. Characterization of microfluidic contact lenses. (a) Fluid flow characterization with fluorescein aqueous solution. Five consecutive injections amounting to $1 \mu \mathrm{L}$ each were performed from the indicated injection site. Within $560 \mathrm{~ms}$, the fluid reached all the sensing sites. Scale bar: $4.0 \mathrm{~mm}$. (b) Characterization of contact lens sensors with artificial tear fluid. Photographs of a contact lens sensor before (i) and after (ii) artificial tear fluid injection. Scale bars: $4.0 \mathrm{~mm}$. Insets 
show micrographs of a sensing cavity and of a channel section. Scale bars: $200 \mu \mathrm{m}$. (c) Representation of smartphone readouts on contact lens sensors before (i) and after (ii) artificial tear fluid injection. The $\mathrm{pH}$ sensor yielded a color shift from green to blue, corresponding to $\mathrm{pH}$ 8.0. The glucose sensor yielded a shift from yellow to green, detecting a concentration of $5.0 \mathrm{mmol}$ $\mathrm{L}^{-1}$. The protein sensor exhibited a light blue color upon interacting with the solution, corresponding to a concentration of $5 \mathrm{~g} \mathrm{~L}^{-1}$. The nitrite sensor reflected an intense pink color, corresponding to a concentration of $120 \mu \mathrm{mol} \mathrm{L}{ }^{-1}$. Scale bar: $300 \mu \mathrm{m}$. (d) Red, Green, and Blue color shift over time for $\mathrm{pH}$ (i), glucose (ii), protein (iii), and nitrite (iv) biochemical sensors, where $\mathrm{t}=0$ is set as the time in which the artificial tear fluid reaches each respective sensing area. $\mathrm{pH}$ color saturation takes place after $5 \mathrm{~s}$, glucose after $15 \mathrm{~s}$, protein from $10 \mathrm{~s}$, and nitrite at $15 \mathrm{~s}$. Overall, readouts can be performed after 15 s. Color insets show the color evolution over time, corresponding to the discrete time values indicated in the $\mathrm{x}$ axis of the graphs. Scale bar: $200 \mu \mathrm{m}$. (e) CIE 1931 chromaticity diagrams obtained with the algorithm after inputting the imaged sensors. The algorithm allowed to select the region of interest, indicated with black dotted lines. The corresponding normalized color is plotted in the chromaticity space calibrated with the points of the sensor of interest (white dots), and compared to the calibration values (black dots). The nearest calibration point gives the concentration readout. Readouts refer to $\mathrm{pH}$ (i), glucose (ii), protein (iii), and nitrite (iv) sensors. Scale bars: $300 \mu \mathrm{m}$. (f) Smartphone-MATLAB algorithm readouts for $\mathrm{pH}$ (i), glucose (ii), protein (iii) and nitrites (iv), before and after artificial tear fluid injection. The y axis indicates the nearest neighbor error (NN Error), intended as the distance to the nearest calibration point in the CIE 1931 chromaticity space. Error bars are plotted in the secondary y axis. 


\section{Discussion}

Tear $\mathrm{pH}$ sensors will exhibit a green color in healthy eyes. A yellow color may indicate a slightly acidic $\mathrm{pH}$, attributed to an alteration of tear buffering capacity. ${ }^{18} \mathrm{pH}$ sensors will reflect a blue color in cases of alkaline $\mathrm{pH}$, which may aid the early detection of rosacea disease. ${ }^{17}$ Tear glucose sensors will exhibit a yellow-greenish color in healthy conditions. Down-regulated sugar levels will result in a null detection by this sensor, which will exhibit a clear yellow color. Upregulated glucose will display increasingly darker green colors when the glucose content increases. The range of interest for the tear glucose sensor is 0 to $5 \mathrm{mmol} \mathrm{L}^{-1} \cdot{ }^{55}$ The protein sensor will always display a light blue color, with the concentration given by the color intensity. An intense light blue will be displayed for healthy protein levels, of $5 \mathrm{~g} \mathrm{~L}^{-1}$ and above. Lower intensities are indicative of the presence of down-regulated proteins in the tear film, which may be related to the development of keratoconus, a disorder of the eye that results in the cornea progressively bulging into a conical shape. ${ }^{29}$ Keratoconus patients have tear protein levels around $3 \mathrm{~g} \mathrm{~L}^{-1}$, even in early stages of the disease. ${ }^{29}$ In these cases, the protein sensor will display a light blue color with low intensity, which can be successfully detected with the algorithm. Tear nitrite sensors will always display a pink color, with varying intensity based on the concentration. An intense pink color will be associated to healthy tears (nitrite levels $\left.\approx 120 \mu \mathrm{mol} \mathrm{L}^{-1}\right)^{31}$. A light pink color may be associated to uveitis (nitrite levels $\approx 80 \mu \mathrm{mol} \mathrm{L}{ }^{-1}$ ). ${ }^{31}$

A contact lens sensor comprised a single microfluidic system consisting of one ring and four branches where the liquid was guided by capillarity toward four sensing areas. Selective hydrophilization of the microfluidic channel was achieved by oxygen plasma treatment at $100 \mathrm{~W}$ for 80 seconds. A flexible shadow mask was laser-patterned such to protect the entire surface of the contact lens, except for the central ring of the microfluidic system. Hydrophobic cavities were 
preferred to embed liquid-state biochemical sensors and reduce leakage. An alternative method to reduce leakage could be to embed either paper or cotton pads soaked in biochemical sensors within the cavities in solid form. The device is designed for a single detection, rather than continuous monitoring. However, it may be emptied, disinfected, and reused.

The diameter of the contact lens and the position of the microfluidic system within the contact lens dictate the portion of the eye surface over which biochemical sensors will be located during wearing. Contact lenses of different diameters may be patterned with the proposed method. If overlying the iris, colorimetric smartphone readouts may need to be calibrated based on the iris color of the patient's eye. Alternatively, biochemical sensors may be embedded in paper/cotton pads and deposited in a solid form, or liquid-state biochemical sensors may be poured over a hydrophobic white plastic substrate. However, this may be simplified by using scleral contact lenses, where the microfluidic system can be inscribed such that colorimetric sensors fall over the white scleral area. To address the influence of ambient light levels toward the resulting RGB triplet, the smartphone app may include a preliminary step of detecting ambient light hitting the sensors and filtering it out for readout. Colorimetric test strips may also be used for comparison. Contact lens biosensing platforms are highly desirable in personalized medicine with a variety of applications. The composition of the tear fluid is altered by the collection method ${ }^{46}$. Analyzing the tear fluid composition directly on-eye allows to skip the sample collection step, simplifying the process and reducing contamination risks. The RGB characterization of the sensors was performed with Color Name smartphone app ${ }^{54}$, installed on an iPhone 6s. The measurement was performed at 200 lux of ambient light conditions. Biochemical sensing solutions were pipetted into individual cuvettes for visible spectroscopy, and imaged at normal incidence, at a distance of 5.0 
$\mathrm{cm}$. The injection of fluorescein solution resulted in the channel being filled in $560 \mathrm{~ms}$, on average, with a capacity of $5 \mu \mathrm{L}$. The overall color change could be assessed after 15 seconds.

\section{Conclusion}

Commercial contact lenses were inscribed using laser light to obtain a microfluidic system where $\mathrm{pH}$, glucose, protein and nitrite chemical sensors were embedded to detect tear fluid metabolites with a colorimetric method. The $\mathrm{pH}$ sensor yielded a sensitivity of $12.23 \mathrm{~nm} / \mathrm{pH}$ and a LOD of $0.25 \mathrm{pH}$ units. The glucose sensor yielded a sensitivity of $1.4 \mathrm{~nm} / \mathrm{mmolL}^{-1}$ of glucose and a LOD of $1.84 \mathrm{mmolL}^{-1}$. The protein sensor yielded a sensitivity of $0.49 \mathrm{~nm} / \mathrm{gL}^{-1}$ of proteins and a LOD of $0.63 \mathrm{gL}^{-1}$. The nitrite sensor yielded a sensitivity of $0.03 \mathrm{~nm} / \mu \mathrm{molL}-1$ of nitrites and a LOD of $24.43 \mu \mathrm{molL}^{-1}$. The contact lens sensor was tested with artificial tears and results were readout using a customized smartphone-MATLAB algorithm interface calibrated to output discrete values. This proof of concept device may be fined to aid the diagnosis and the monitoring of a range of diseases, including rosacea, diabetes, keratoconus, and uveitis.

\section{Materials and methods}

Materials. Deionized water, D-(+)-glucose $(99.5 \%)$, protein standard $\left(200 \mathrm{mg} \mathrm{mL}^{-1}\right), \mathrm{pH}$ indicators (bromothymol blue, methyl red, and phenolphthalein), glucose sensor (glucose oxidase, peroxidase, and 3,3',5,5'-tetramethylbenzidine), protein sensor (3',3",5',5"-tetrachlorophenol3,4,5,6-tetrabromosulfophthalein), nitrite sensor (sulfanilamide, $\mathrm{N}$-(1-naphthyl)- ethylenediamine dihydochloride), trizma hydrochloride, tryzma base, sodium fluorescein, and phosphate buffered saline (PBS) tablets were purchased from Sigma-Aldrich. Systane artificial tears were purchased online. RGB contact lenses based on Boston XO (fluorosilicone acrylate) material were supplied by No7 Contact Lenses, UK. 
Equipment. A benchtop $\mathrm{pH}$ meter with a resolution of 0.1 was purchased from Mettler Toledo. UV-VIS Flame Spectrometer, optical fibers, disposable VIS cuvettes, cuvette holder, and tungsten light source were used for absorbance spectroscopy and purchased from Ocean Optics. Color name application was installed on an iPhone 6s for RGB characterization. The readout algorithm was developed with MATLAB, using the Computational Color Science toolbox.

Preparation of Chromogenic Solutions. The $\mathrm{pH}$ biosensor was synthesized using bromothymol blue $(28 \mu \mathrm{g})$, methyl red $(2.5 \mu \mathrm{g})$ and phenolphthalein $(18 \mu \mathrm{g})$. The glucose biosensor was prepared diluting 3,3',5,5'-tetramethylbenzidine (210 $\mu \mathrm{g})$, GOD (18 U) and POD (105 U) in DI water. The protein sensor contained 3',3",5',5"-tetrachlorophenol-3,4,5,6-tetrabromosulfophthalein (28 $\mu \mathrm{g})$. The nitrite sensor contained 3-hydroxy-1,2,3,4-tetrahydro-7,8-benzoquinoline $(68 \mu \mathrm{g})$ and sulfanilamide $(60 \mu \mathrm{g})$.

Preparation of Buffer Solutions. Phosphate buffered saline (PBS) solutions were prepared dissolving one PBS tablet in $200 \mathrm{~mL}$ of deionized water, yielding $0.01 \mathrm{M}$ phosphate buffer, 0.0027 $\mathrm{M}$ potassium chloride and $0.137 \mathrm{M}$ sodium chloride, with a pH of 7.4 at $25^{\circ} \mathrm{C}$. Glucose solutions of $2.0 \mathrm{mmol} \mathrm{L}^{-1}, 5.0 \mathrm{mmol} \mathrm{L}^{-1}, 10.0 \mathrm{mmol} \mathrm{L}^{-1}, 15.0 \mathrm{mmol} \mathrm{L}^{-1}$, and $20.0 \mathrm{mmol} \mathrm{L}^{-1}$ were prepared by dissolving the respective amounts of D-(+)-Glucose in PBS. Protein standard solution was dissolved in PBS to produce protein solutions with concentrations of $0.5 \mathrm{~g} \mathrm{~L}^{-1}, 1.0 \mathrm{~g} \mathrm{~L}^{-1}, 2.0 \mathrm{~g} \mathrm{~L}^{-}$ 1, $3.0 \mathrm{~g} \mathrm{~L}^{-1}, 4.0 \mathrm{~g} \mathrm{~L}^{-1}$, and $5.0 \mathrm{~g} \mathrm{~L}^{-1}$. Sodium nitrite was dissolved in DI water to obtain concentrations of $10,20,80,120,150,180$, and $200 \mu \mathrm{mol} \mathrm{L}^{-1}$. $\mathrm{pH}$ buffer solutions $(\mathrm{pH} 6.0,6.5$, 7.0, 7.3, 7.6, and 8.0) were prepared with Trizma Hydrochloride and Trizma base.

Preparation of artificial tear fluid. Artificial tear fluid was prepared using Systane eye drops (ingredients: polyethylene glycol 400, boric acid, calcium chloride, magnesium chloride, potassium chloride, purified water, sodium chloride), $5 \mathrm{mmol} \mathrm{L}^{-1}$ of D-(+)-glucose, $120 \mu \mathrm{mol} \mathrm{L}^{-1}$ 
nitrites/nitrates, $5 \mathrm{~g} \mathrm{~L}^{-1}$ protein standard, and DI water. The solution was adjusted to a $\mathrm{pH}$ of 8.0 using Trizma hydrochloride and Trizma base.

Fabrication of the microfluidic system. RGP contact lenses were processed by laser ablation, using a Rayjet $\mathrm{CO}_{2}$ laser engraver, at a power of $60 \%$ and speed of $40 \%$, selecting acrylate materials. The layout of the microchannel was previously designed on CorelDraw software, and it consisted on a $1.5 \mathrm{~mm}$ wide channel ring with an internal diameter of $6.5 \mathrm{~mm}$. Microcavities had a diameter of $2.0 \mathrm{~mm}$. The same design was patterned on a plastic shadow mask, which was used to selectively hydophylize the microchannel with oxygen plasma treatment $(100 \mathrm{~W}, 80 \mathrm{~s})$.

Smartphone-MATLAB readouts. The customized MATLAB algorithm was based on RGB image processing. Calibration points consisted on photographs of solutions at different concentration levels of $\mathrm{pH}$, glucose, protein, and nitrite, which exhibited different colors. The $\mathrm{pH}$ sensor was calibrated at values of 6.0, 6.5, 7.0, 7.3, 7.6, and 8.0. The glucose sensor was calibrated at values of $2.0,5.0,10.0,15$, and $20 \mathrm{mmol} \mathrm{L}^{-1}$. The protein sensor was calibrated at values of 0.5 , 1.0, 2.0, 3.0, 4.0, and $5.0 \mathrm{~g} \mathrm{~L}^{-1}$. The nitrite sensor was calibrated at values of $10,20,50,80,120$, 150, 180, and $200 \mu \mathrm{mol} \mathrm{L}-1$. Solutions $(400 \mu \mathrm{L})$ were hosted in plastic cuvettes and photographed at normal incidence, a distance of $5.0 \mathrm{~cm}$, and at ambient light conditions of 200 lux. The MATLAB algorithm processed these images and located their mean color, identified by RGB triplets, on the chromaticity space. Sensors readouts were based on the comparison between the chromaticity coordinates of the sensors with unknown concentration and the previously stored coordinates of the calibration points. The algorithm outputted the concentration values corresponding to the calibration point that was nearest to the mean color of the sensor under examination. 


\section{Author contributions}

R.M. and A.K.Y. conceived the idea. R.M. performed the experiments and wrote the manuscript. A.K.Y., D.V. and J.S.W., supervised the work and made intellectual contributions.

\section{Conflict of interest}

There is no conflict to declare.

\section{AKNOWLEDGEMENTS}

R.M. thanks James Procter (No7 Contact Lenses, UK) for supplying RGP contact lenses, and the School of Chemical Engineering at the University of Birmingham for funding.

\section{AUTHOR INFORMATION}

\section{Corresponding Author}

*r.moreddu18@imperial.ac.uk

\section{References}

1. Lei, Z.; Beuerman, R. W.; Chew, A. P.; Koh, S. K.; Cafaro, T. A.; Urrets-Zavalia, E. A.; Urrets-Zavalia, J. A.; Li, S. F.; Serra, H. M., Quantitative analysis of N-linked glycoproteins in tear fluid of climatic droplet keratopathy by glycopeptide capture and iTRAQ. $J$ Proteome Res 2009, 8 (4), 1992-2003.

2. $\quad$ Park, M.; Jung, H.; Jeong, Y.; Jeong, K. H., Plasmonic Schirmer Strip for Human TearBased Gouty Arthritis Diagnosis Using Surface-Enhanced Raman Scattering. ACS Nano 2017, 11 (1), 438-443.

3. Zhou, L.; Beuerman, R. W.; Chan, C. M.; Zhao, S. Z.; Li, X. R.; Yang, H.; Tong, L.; Liu, S.; Stern, M. E.; Tan, D., Identification of tear fluid biomarkers in dry eye syndrome using iTRAQ quantitative proteomics. J Proteome Res 2009, 8 (11), 4889-905.

4. An, H. J.; Ninonuevo, M.; Aguilan, J.; Liu, H.; Lebrilla, C. B.; Alvarenga, L. S.; Mannis, M. J., Glycomics analyses of tear fluid for the diagnostic detection of ocular rosacea. J Proteome Res 2005, 4 (6), 1981-7.

5. Tomosugi, N.; Kitagawa, K.; Takahashi, N.; Sugai, S.; Ishikawa, I., Diagnostic potential of tear proteomic patterns in Sjogren's syndrome. J Proteome Res 2005, 4 (3), 820-5. 
6. $\quad$ Sempionatto, J. R.; Brazaca, L. C.; Garcia-Carmona, L.; Bolat, G.; Campbell, A. S.; Martin, A.; Tang, G.; Shah, R.; Mishra, R. K.; Kim, J.; Zucolotto, V.; Escarpa, A.; Wang, J., Eyeglasses-based tear biosensing system: Non-invasive detection of alcohol, vitamins and glucose. Biosens Bioelectron 2019, 137, 161-170.

7. Leonard A. Levin, S. F. E. N., James Ver Hoeve, Samuel Wu, Paul L. Kaufman, Albert Alm, Physiology of the Eye. Elsevier: 2011.

8. Chen, F. S.; Maurice, D. M., The Ph in the Precorneal Tear Film and under a ContactLens Measured with a Fluorescent-Probe. Exp Eye Res 1990, 50 (3), 251-259.

9. Yoshiki Ohashi, M. D., Kazuo Tsubota, Laboratory findings in tear fluid analysis. Clinica Chimica Acta 369, 17-28.

10. Hagan, S.; Martin, E.; Enriquez-de-Salamanca, A., Tear fluid biomarkers in ocular and systemic disease: potential use for predictive, preventive and personalised medicine. EPMAJ 2016, 7 (15), 15.

11. Masmali, A. M.; Purslow, C.; Murphy, P. J., The tear ferning test: a simple clinical technique to evaluate the ocular tear film. Clin Exp Optom 2014, 97 (5), 399-406.

12. Li, N.; Wang, N.; Zheng, J.; Liu, X. M.; Lever, O. W.; Erickson, P. M.; Li, L., Characterization of human tear proteome using multiple proteomic analysis techniques. $J$ Proteome Res 2005, 4 (6), 2052-61.

13. Fischer, F. H.; Wiederholt, M., Human precorneal tear film $\mathrm{pH}$ measured by microelectrodes. Graefes Arch Clin Exp Ophthalmol 1982, 218 (3), 168-70.

14. Abelson, M. B.; Udell, I. J.; Weston, J. H., Normal Human Tear Ph by Direct Measurement. Arch Ophthalmol-Chic 1981, 99 (2), 301-301.

15. Carney, L. G.; Mauger, T. F.; Hill, R. M., Tear Buffering in Contact-Lens Wearers. Acta Ophthalmologica 1990, 68 (1), 75-79.

16. Ahmed, I.; Patton, T. F., Effect of Ph and Buffer on the Precorneal Disposition and Ocular Penetration of Pilocarpine in Rabbits. International Journal of Pharmaceutics 1984, 19 (2), 215-227.

17. Abelson, M. B.; Sadun, A. A.; Udell, I. J.; Weston, J. H., Alkaline Tear Ph in Ocular Rosacea. American Journal of Ophthalmology 1980, 90 (6), 866-869.

18. Norn, M., Tear pH after instillation of buffer in vivo. Acta Ophthalmol Suppl 1985, 173, $32-4$.

19. Thygesen, J. E. M.; Jensen, O. L., Ph Changes of the Tear Fluid in the Conjunctival Sac during Postoperative Inflammation of the Human-Eye. Acta Ophthalmologica 1987, 65 (2), 134136.

20. Karns, K.; Herr, A. E., Human tear protein analysis enabled by an alkaline microfluidic homogeneous immunoassay. Anal Chem 2011, 83 (21), 8115-22.

21. Dor, M.; Eperon, S.; Lalive, P. H.; Guex-Crosier, Y.; Hamedani, M.; Salvisberg, C.; Turck, N., Investigation of the global protein content from healthy human tears. Exp Eye Res 2019, 179, 64-74.

22. Zhao, Z. J.; Liu, J. F.; Wasinger, V. C.; Malouf, T.; Nguyen-Khuong, T.; Walsh, B.; Willcox, M. D. P., Tear lipocalin is the predominant phosphoprotein in human tear fluid. Exp Eye Res 2010, 90 (2), 344-349.

23. Kim, H. J.; Kim, P. K.; Yoo, H. S.; Kim, C. W., Comparison of tear proteins between healthy and early diabetic retinopathy patients. Clin Biochem 2012, 45 (1-2), 60-7.

24. Chiang, S. Y.; Tsai, M. L.; Wang, C. Y.; Chen, A.; Chou, Y. C.; Hsia, C. W.; Wu, Y. F.; Chen, H. M.; Huang, T. H.; Chen, P. H.; Liu, H. T.; Shui, H. A., Proteomic analysis and 
identification of aqueous humor proteins with a pathophysiological role in diabetic retinopathy. $J$ Proteomics 2012, 75 (10), 2950-9.

25. Csosz, E.; Boross, P.; Csutak, A.; Berta, A.; Toth, F.; Poliska, S.; Torok, Z.; Tozser, J., Quantitative analysis of proteins in the tear fluid of patients with diabetic retinopathy. $J$ Proteomics 2012, 75 (7), 2196-204.

26. Ihnatko, R.; Eden, U.; Lagali, N.; Dellby, A.; Fagerholm, P., Analysis of protein composition and protein expression in the tear fluid of patients with congenital aniridia. $J$ Proteomics 2013, 94, 78-88.

27. Soria, J.; Duran, J. A.; Etxebarria, J.; Merayo, J.; Gonzalez, N.; Reigada, R.; Garcia, I.; Acera, A.; Suarez, T., Tear proteome and protein network analyses reveal a novel pentamarker panel for tear film characterization in dry eye and meibomian gland dysfunction. J Proteomics 2013, 78, 94-112.

28. Davidson, H. J.; Kuonen, V. J., The tear film and ocular mucins. Vet Ophthalmol 2004, 7 (2), 71-7.

29. Balasubramanian, S. A.; Pye, D. C.; Willcox, M. D., Levels of lactoferrin, secretory IgA and serum albumin in the tear film of people with keratoconus. Exp Eye Res 2012, 96 (1), 132-7. 30. Salonen, E. M.; Tervo, T.; Torma, E.; Tarkkanen, A.; Vaheri, A., Plasmin in tear fluid of patients with corneal ulcers: basis for new therapy. Acta Ophthalmol (Copenh) 1987, 65 (1), 312.

31. Mirza, G. E. K., S.; Er, M.; Güngörmüs, N.; Karaküçükb, I.; Saraymen, R., Tear Nitrite and Nitrate Levels as Nitric Oxide End Products in Patients with Behçet's Disease and NonBehçet's Uveitis. Ophthalmic research 2001, 33, 48-51.

32. Lane, J. D.; Krumholz, D. M.; Sack, R. A.; Morris, C., Tear glucose dynamics in diabetes mellitus. Current Eye Research 2006, 31 (11), 895-901.

33. Zhang, J.; Hodge, W.; Hutnick, C.; Wang, X., Noninvasive diagnostic devices for diabetes through measuring tear glucose. J Diabetes Sci Technol 2011, 5 (1), 166-72.

34. Chen, C.; Dong, Z.-Q.; Shen, J.-H.; Chen, H.-W.; Zhu, Y.-H.; Zhu, Z.-G., 2D Photonic Crystal Hydrogel Sensor for Tear Glucose Monitoring. ACS Omega 2018, 3 (3), 3211-3217.

35. Ruan, J. L.; Chen, C.; Shen, J. H.; Zhao, X. L.; Qian, S. H.; Zhu, Z. G., A Gelated Colloidal Crystal Attached Lens for Noninvasive Continuous Monitoring of Tear Glucose. Polymers (Basel) 2017, 9 (4), 125.

36. Alexeev, V. L.; Das, S.; Finegold, D. N.; Asher, S. A., Photonic crystal glucose-sensing material for noninvasive monitoring of glucose in tear fluid. Clin Chem 2004, 50 (12), 2353-60.

37. Yang, X.; Pan, X.; Blyth, J.; Lowe, C. R., Towards the real-time monitoring of glucose in tear fluid: holographic glucose sensors with reduced interference from lactate and $\mathrm{pH}$. Biosens Bioelectron 2008, 23 (6), 899-905.

38. Manju, S.; Hari, P. R.; Sreenivasan, K., Fluorescent molecularly imprinted polymer film binds glucose with a concomitant changes in fluorescence. Biosens Bioelectron 2010, 26 (2), 894-7.

39. Elsherif, M.; Hassan, M. U.; Yetisen, A. K.; Butt, H., Wearable Contact Lens Biosensors for Continuous Glucose Monitoring Using Smartphones. ACS Nano 2018, 12 (6), 5452-5462. 40. Yao, H.; Shum, A. J.; Cowan, M.; Lahdesmaki, I.; Parviz, B. A., A contact lens with embedded sensor for monitoring tear glucose level. Biosens Bioelectron 2011, 26 (7), 3290-6. 41. Yu-Te Liao, H. Y., Andrew Lingley, Babak Parviz, Brian P. Otis, A 3-W CMOS Glucose Sensor for Wireless Contact-Lens Tear Glucose Monitoring. IEEE Journal of Solid-State Circuits 2012, 47 (1). 
42. Yao, H.; Liao, Y.; Lingley, A. R.; Afanasiev, A.; Lahdesmaki, I.; Otis, B. P.; Parviz, B. A., A contact lens with integrated telecommunication circuit and sensors for wireless and continuous tear glucose monitoring. Journal of Micromechanics and Microengineering 2012, 22

(7).

43. Iguchi, S.; Kudo, H.; Saito, T.; Ogawa, M.; Saito, H.; Otsuka, K.; Funakubo, A.; Mitsubayashi, K., A flexible and wearable biosensor for tear glucose measurement. Biomedical Microdevices 2007, 9 (4), 603-609.

44. Yetisen, A. K.; Jiang, N.; Tamayol, A.; Ruiz-Esparza, G. U.; Zhang, Y. S.; MedinaPando, S.; Gupta, A.; Wolffsohn, J. S.; Butt, H.; Khademhosseini, A.; Yun, S. H., Paper-based microfluidic system for tear electrolyte analysis. Lab on a Chip 2017, 17 (6), 1137-1148.

45. Yan, Q.; Peng, B.; Su, G.; Cohan, B. E.; Major, T. C.; Meyerhoff, M. E., Measurement of tear glucose levels with amperometric glucose biosensor/capillary tube configuration. Anal Chem 2011, 83 (21), 8341-6.

46. Haeringen, N. J.; Glasius, E., Collection method dependant concentrations of some metabolites in human tear fluid, with special reference to glucose in hyperglycaemic conditions. Albrecht von Graefes Archiv fr Klinische und Experimentelle Ophthalmologie 1977, 202 (1), 1-7. 47. Taormina, C. R.; Baca, J. T.; Asher, S. A.; Grabowski, J. J.; Finegold, D. N., Analysis of tear glucose concentration with electrospray ionization mass spectrometry. Journal of the American Society for Mass Spectrometry 2007, 18 (2), 332-336.

48. Haggerty, C. M.; Larke, J. R., Human Tear Protein-Fractions during Waking Hours. Ophthal Physl Opt 1982, 2 (3), 187-191.

49. Yetisen, A. K.; Moreddu, R.; Seifi, S.; Jiang, N.; Vega, K.; Dong, X.; Dong, J.; Butt, H.; Jakobi, M.; Elsner, M.; Koch, A. W., Dermal Tattoo Biosensors for Colorimetric Metabolite Detection. Angew Chem Int Ed Engl 2019.

50. $\quad$ Elsherif, M.; Hassan, M. U.; Yetisen, A. K.; Butt, H., Hydrogel optical fibers for continuous glucose monitoring. Biosens Bioelectron 2019, 137, 25-32.

51. Elsherif, M.; Moreddu, R.; Hassan, M. U.; Yetisen, A. K.; Butt, H., Real-time optical fiber sensors based on light diffusing microlens arrays. Lab Chip 2019, 19 (12), 2060-2070.

52. Moreddu, R.; Elsherif, M.; Butt, H.; Vigolo, D.; Yetisen, A. K., Contact lenses for continuous corneal temperature monitoring. RSC Advances 2019, 9 (20), 11433-11442.

53. Moreddu, R.; Vigolo, D.; Yetisen, A. K., Contact Lens Technology: From Fundamentals to Applications. Adv Healthc Mater 2019, e1900368.

54. Color Name (Smartphone application). Developer: Vlad Polyanskiy. Downloaded October 2018 on iPhone 6s. https://itunes.apple.com/gb/app/color-name-ar/id906955675? mt=8.

55. D. K. Sen, G. S. S., Tear glucose levels in normal people and in diabetic patients. British Journal of Ophthalmology 1980, 64 (9), 693-695. 